\title{
Assessment of systemic vulnerability in flood prone areas
}

\author{
S. Pascale, L. Giosa, F. Sdao \& A. Sole \\ Basilicata University, Potenza, Italy
}

\begin{abstract}
This paper deals with the conception, the development and the subsequent validation of an integrated numerical model for the assessment of systemic vulnerability in complex and urbanized areas subject to flood risk. The proposed model, which is based on the studies of Tamura et al. (Eu. J. Oper. Res., 2000) and Pascale et al. (Ad. Geo., 2007) considers vulnerability not as a characteristic of a particular element at risk, but as a peculiarity of a complex territorial system, in which different elements are reciprocally linked in a functional way. Therefore, it facilitates the identification, in selected areas, of the elements that are mainly responsible for functional loss and which thus make the whole system critical. This feature makes the proposed model effectively able to support correct territorial planning and suitable management of an emergency following natural disasters that trigger or remobilize mass movements.
\end{abstract}

Keywords: systemic vulnerability, territorial system, network of influence between the diverse nodes.

\section{Introduction}

Floods events can sometimes produce catastrophic effects on a given territory. Not only do they often cause loss of human lives but they can also cause more or less serious damage to the so-called "vulnerable elements" of the territory, such as buildings or infrastructure as well as causing damage and temporary or permanent malfunctioning of economic, service and productive activities. This work puts forward a model of vulnerability to flood risk in anthropic areas defined as Systemic Vulnerability [2, 4, 9]; a model which has already been proposed for the study of systemic vulnerability in landslide prone areas [10,11], modified to account for the specific vulnerability of flood events. The model is 
based on the application of a mathematical-decisional model able to assess the level of flood risk of a system on the basis of an analysis of disturbing and stress provoking agents acting on the system itself. The methodology utilized is based on an influence network that takes into consideration the functional relationships existing among the elements making up the territorial system. The proposed assessment model is based on the studies of Tamura et al., 2000 [12], Ezell et al., 2000 [3], Haimes and Jiang, 2001 [7], Minciardi et al., 2004 [9], Pascale et al., 2007 [11], Giosa et al., 2008 [6] and Pascale et al., 2008 [10], and regards vulnerability not as a characteristic of a particular element at risk but as the specificity of a complex territorial system whose diverse elements are functionally related.

\section{Assessment of systemic vulnerability of complex territorial systems in flood prone areas: the proposed model}

This model, anchored in a GIS system, features the following phases:

1. The first phase aims at the topological characterization of the studied territorial system and the assessment of the scenarios in terms of flood hazard.

2. The second phase deals with the analysis of the direct consequences of a scenario event on the system;

3. The third phase focuses on the definition of the assessment model of the systemic vulnerability in areas subject to floods;

4. The fourth phase concerns the implementation of the proposed model inside a GIS system;

The proposed model has been applied with good results on the territory of the city of Potenza, which is well known for its critical hydrogeological context.

\subsection{Phase 1: characterization of the system}

Complex territorial systems are made up of many sub systems with specific functions (e.g., inhabited settlements, health centers, environmental and civil protection structures, different infrastructures, energy distribution etc.); which are (well or badly) connected by causal and reciprocal relationships whose interactions are necessary to ensure a satisfactory and efficient functioning of the complex system.

The characterization of the system is itself made up of three phases: characterization of the network, scenario analysis, overlay mapping of the information.

In this way a territorial system is represented by a network $G(E, A),[10 ; 11]$ where $\mathrm{E}$ is the set of nodes and $\mathrm{A}$ is the set of links (fig. 2). The nodes belonging to the set E represent all the relevant territorial elements for the territorial system. Damage to or malfunctioning of one of these elements can have a significant influence on the proper functioning of the entire territorial system. Such nodes can represent specific territorial points (such as hospitals or police stations), linear elements (such as roadway infrastructure) or areas (such as industrial areas or sites). 
The links belonging to set $\mathrm{A}$, on the other hand, represent the relationships of influence between the functionalities of the diverse territorial elements, i.e. between the diverse nodes. Specifically an element can be said to "influence" another element when the destruction or reduced efficiency of the first element has a negative effect on the functionality of the second.

It was necessary to characterize the system in relation to the particular damage scenarios chosen. They were chosen for periods of return relative to $\mathrm{T}=$ $50, \mathrm{~T}=200$ and $\mathrm{T}=500$ years.

The specific damage scenarios chosen were superimposed on the map of the location of the elements of the network under study so as to identify the elements directly involved in a possible catastrophic event.

The assessment of the entire functionality of a territorial system requires a consideration of the relationships existing between its subsystems and thus an analysis of the vulnerability of a territorial system requires not only an analysis of its single components but also of the relationships between them $[1,13]$.

\subsection{Phase 2: Analyses of external stress on the elements}

In this phase the elements directly involved in a possible catastrophe are considered at each node of the elements belonging to the set $\mathrm{E}(\mathrm{i}=1, \ldots \mathrm{N})$, where $\mathrm{N}$ is the number of territorial elements considered:

$\bar{\xi}_{i}$

vector of external solicitation in relation to flood risk agents on the ' $i$-th territorial element.

$y_{i} \quad$ function of vulnerability of the $i$-th element with respect to flood risk.

$x_{i}^{0} \quad$ level of intrinsic functionality or the level of functional integrity of the element $i$ evaluated exclusively on the basis of its physical integrity.

I. Vector of external solicitation in relation to flood risk agent on the ' $i$-th territorial element $\left(\bar{\xi}_{i}\right)$. The magnitude is measured by means of a matrix (tab. 1) constituted by various parameters: hydraulic level and speed. Each parameter is assigned a number/score between 1 and 10 as a function of its specific interval and class. These numbers are then added and subdivided into opportune intervals. Each interval has an associated magnitude varying from 1 to 10 and an intensity varying from very low (I) to extremely high (X).

II.Function of vulnerability of the $i$-th element with respect to flood risk $\left(y_{i}\right)$.

The vulnerability of elements exposed to risk varying between 0 ( no loss) and 1 (total loss), is calculated using the following equation:

$$
y=1-a \cdot \frac{e^{-\alpha \xi^{2,2}}}{\left(1+e^{-\alpha \xi^{2,2}}\right)}
$$


Table 1: $\quad$ Magnitude and intensity of the flood.

\begin{tabular}{|c|c|c|c|c|c|c|c|c|c|c|}
\hline PARAMETER & \multicolumn{10}{|c|}{ RANGE OF VALUES } \\
\hline HYDRAULIC LEVEL (m) & $0-1,5$ & $1,51-2$ & $2,1-2,5$ & $2,51-3$ & $3,1-4$ & $4,1-5$ & $5,1-6$ & $6,1-7$ & $7,1-8$ & $>8$ \\
\hline Rating & 0,1 & 0,2 & 0,3 & 0,4 & 0,5 & 0,6 & 0,7 & 0,8 & 0,9 & $l$ \\
\hline SPEED (m/s) & $0-1$ & $1,1-2$ & $2,1-3$ & $3,1-4$ & $4,1-5$ & $5,1-6$ & $6,1-7$ & $7,1-8$ & $8,1-9$ & $>9$ \\
\hline Rating & 0,1 & 0,2 & 0,3 & 0,4 & 0,5 & 0,6 & 0,7 & 0,8 & 0,9 & l \\
\hline TOTAL RATING & $0-0,4$ & $0,5-0,8$ & $0,9-1,2$ & $1,3-1,6$ & $1,7-2$ & $2,2-2,4$ & $2,5-2,8$ & $2,9-3,2$ & $3,3-3,6$ & $3,7-4$ \\
\hline INTENSITY & $I$ & II & III & $\Pi V$ & V & $V I$ & $V I I$ & VIII & $I X$ & $X$ \\
\hline
\end{tabular}

where $\bar{\xi}_{i}$ is the stress in relation to the considered risk; a is a constant which takes on a value equal to 2 and is calculated by fixing the boundary conditions $\left(\bar{\xi}_{i}=0\right.$ and $\mathrm{y}=0$, where $\mathrm{y}=0$ represent $0 \%$ of vulnerability, i.e. no loss); $\alpha$ is a variable which depends on the typology of the risk element

The vulnerability curves were corrected as a function of population density $\mathrm{f}$ that assumes a value of 0 if population density is less than $5000 \mathrm{Ab} / \mathrm{km}^{2}$ (ISTAT census 2001); 0.2 if the population density is between 5000 and $100000 \mathrm{Ab} / \mathrm{km}^{2}$; 0.4 if it is greater than $100000 \mathrm{Ab} / \mathrm{km}^{2}$.

$$
y=1-a \cdot \frac{e^{-\alpha \xi^{(2,2+f)}}}{\left(1+e^{-\alpha \xi^{(2,2+f)}}\right)}
$$

Vulnerable elements such as buildings or communication networks are subdivided into three categories A, B and C. [8].

Category A includes very old buildings of mediocre quality, lacking in foundations and structural connecting elements, constructed outside existing norms (e.g. rural dwellings); category B type constructions which have been subject to structural degradation and means of communication such as local roads and country tracks connecting farmhouses, category B includes traditional brickwork edifices or light prefabricated constructions without re-enforced concrete (single household dwellings or small blocks of apartments) and secondary transport networks i.e. provincial and local roads.

Category C includes good quality concrete buildings or re-enforced prefabricated constructions and primary transport systems such as main highways and railways.

Variations in the parameter $\alpha$ give diverse vulnerability curves for diverse buildings and types of means of communication (fig. 1).

III. Intrinsic Vulnerability $x_{i}^{0}$ of the $i$-th node. Intrinsic vulnerability describes the conditions of functional integrity of territorial elements studied and is directly dependent on their physical vulnerability but does not consider any 


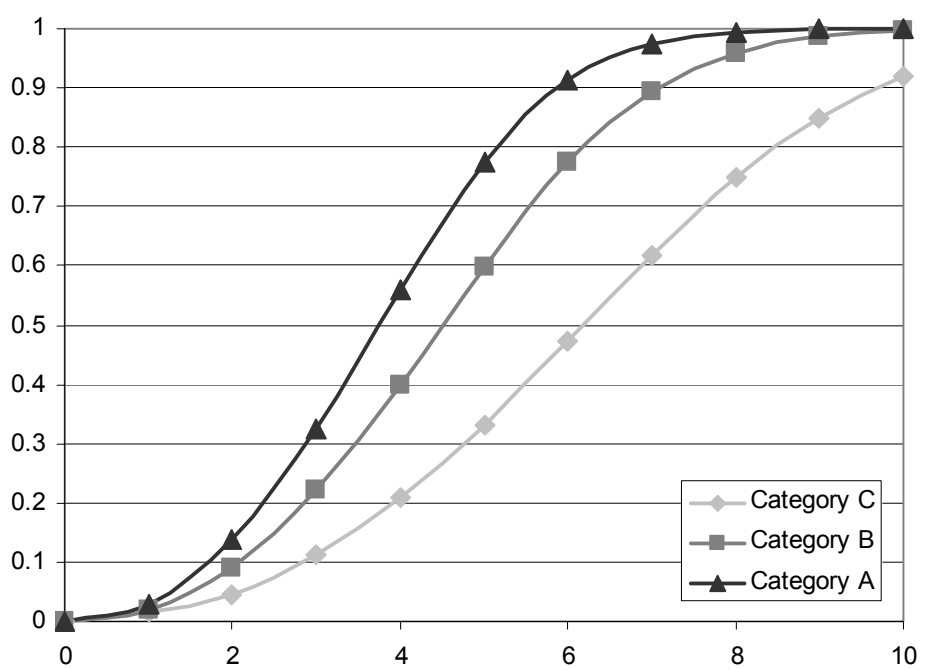

Figure 1: Vulnerability curve for different types of risk elements.

possible functional interconnection with other nodes or entities [5]. The variable expressing the level of intrinsic functionality of an element $x_{i}^{0}$ can take on values within the interval between 0 and $1 ; 1$ indicates a low value of intrinsic functionality (element considered as outside the system) 0 indicates an optimal value of intrinsic functionality. The equation used to calculate intrinsic vulnerability is the following:

$$
x_{i}^{0}=\left(1-0,1 \widetilde{a}_{i}\right) \frac{\left(1-e^{-\widetilde{a}_{i} y_{i}^{2}}\right)}{\left(1-e^{\widetilde{a}_{i}}\right)}+0,1 \widetilde{a}_{i}
$$

$\mathrm{y}_{\mathrm{i}}$ represents the value of vulnerability calculated in the $\mathrm{i}$-th node of equation (1); $\widetilde{\alpha}_{i}$ is a parameter which expresses the relation between the level of functionality $x_{i}^{0}$ of the node $\mathrm{i}$ and the vulnerability $y_{i}$, i.e. it expresses the influence of the level of vulnerability $y_{i}$ of the element $\mathrm{i}$ on its intrinsic functionality $x_{i}^{0}$; this parameter is assigned a weight of $(8,6$ o 2$)$ as a function of vulnerability $y_{i}$ :

$0.8<y_{i}<1 \quad \tilde{\alpha}=8 \rightarrow$ high intrinsic vulnerability;

$0.4<y_{i}<0.8 \quad \widetilde{\alpha}=6 \rightarrow$ medium intrinsic vulnerability;

$0<y_{i}<0.4 \tilde{\alpha}=2 \rightarrow$ low intrinsic vulnerability

\subsection{Phase 3: analyses of systemic vulnerability}

Each node falling within the risk scenario under consideration is attributed a level of functional integrity $x_{i}$ which also takes account of its influence $w_{i j}$ on 
the various entities of the system studied. Following this a global index of the entire system is obtained.

a) Level of functional integrity $x_{i}$ of the $i$-th element

The level of functionality $x_{i}$ describes the conditions of functional integrity of the territorial element associated with the node $\mathrm{i}$ involving information relative to the functioning of the other nodes.

The variable that expresses the level of functionality can also take on values that fall within the interval 0 and 1 , where 0 indicates complete functional integrity and 1 corresponds to a state of total inoperability (poor functional integrity). The following equation is used to describe this dependence:

$$
x_{i}=\min \left(x_{i}^{0}, w_{i j}\left(x_{j}\right), \forall j \in P(i)\right)
$$

where the function $w_{i j}$ expresses the level of influence of the element $\mathrm{j}$ on the level of functionality of the element $i$.

It is possible to assume that the function $\mathrm{w}_{\mathrm{ij}(\mathrm{xj})}$, expressed through the use of a monotonous non-decreasing function, characterized by range and co-range belonging to the interval $[0,1]$ can represent the influence of the functionality of the element $\mathrm{j}$ on the functionality of the element $\mathrm{i}$ through the following expression:

$$
w_{i j}\left(x_{j}\right)=\left(1-0.1 \alpha_{i j}\right) \frac{\left(1-e^{-\alpha_{i j} x_{j}^{2}}\right)}{\left(1-e^{-\alpha_{i j}}\right)}+0.1 \alpha_{i j}
$$

where $\alpha_{i j}$ is a parameter which characterizes the arch, i.e. the relation between the node $\mathrm{i}$ and the node $\mathrm{j}$; note that when the value of $\alpha_{i j}$ increases the level of influence of the functionality of the element $\mathrm{j}$ on the functionality of the element $\mathrm{i}$ decreases and vice versa. The parameter $\alpha_{\mathrm{ij}}$ is calculated through the relation:

$$
a_{i j}=-8,5 \cdot \operatorname{In}+10
$$

where I is the value of the influence calculated among the various risk elements. b) Index of influence

The first step in the definition of the influence between diverse territorial elements consists in the determination of which categories of elements are influenced by which other categories of elements in an emergency phase. The second step is the definition of the level of such influences on the basis of objective information deriving from the analyses of the elements that make up the territorial system under examination. With these objectives, the functions that are able to supply the level of influence between the two categories for each couple of categories have been defined In calculating the level of influence it has 
been hypothesized that both the relation of supply and demand of services and the distance between the two elements considered play an important role in the definition of the level of dependence between them. Therefore for each couple of categories $(\mathrm{a}, \mathrm{b})$ an index of influence $\mathrm{I}_{\mathrm{b}, \mathrm{a}}(\mathrm{tab} .2)$ was introduced and evaluated, these index take on values within the interval $[0,1]$.

Table 2: $\quad$ Equations for the calculation of influence index defined for each couple of categories of territorial elements characterized by functional dependence.

\begin{tabular}{|c|c|c|c|c|c|}
\hline$c^{c} d_{\eta_{0}}$ & settlements & Route links & Headquarters & Health unities & Industries \\
\hline Settlements & 0 & 0 & 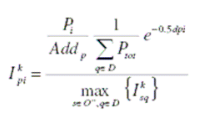 & 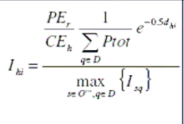 & 0 \\
\hline Route links & $I_{r j}=\frac{a_{r j}}{\sum_{\forall k \in S} a_{r k}}$ & $I_{m j}=\frac{a_{m j}}{\sum_{\forall k \in S} a_{m k}}$ & $I_{h j}=\frac{a_{h j}}{\sum_{\forall k \in S} a_{h k}}$ & $I_{h j}=\frac{a_{h j}}{\sum_{\forall k \in S} a_{h k}}$ & $I_{p m}=\frac{a_{p m}}{\sum_{\forall k \in S} a_{p k}}$ \\
\hline Headquarters & 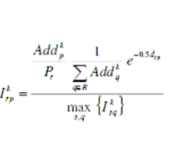 & 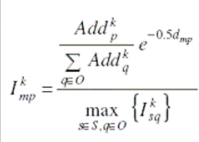 & 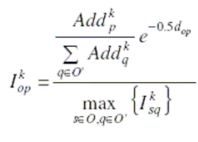 & 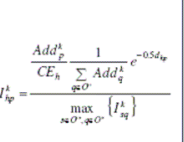 & 0 \\
\hline Health unities & 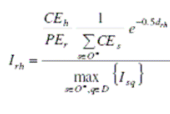 & 0 & 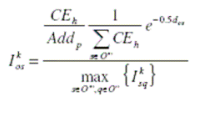 & 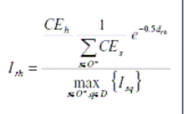 & 0 \\
\hline Industries & 0 & 0 & 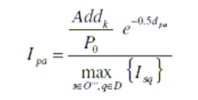 & 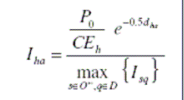 & 0 \\
\hline
\end{tabular}

c) Global Index I of systemic functionality

The final step in the proposed procedure was the calculation of the global index I of systemic functionality defined as the average value of functional integrity of all the elements considered and can be expressed as:

$$
I=\frac{\sum_{i=1}^{N} x_{i}}{N}
$$

This index expresses the value of functional integrity of all the elements considered and it also varies within the interval $[0,1]$ where 0 indicates no functional loss, and 1 total functional loss. Following this, a table (tab. 3) was elaborated as a function of the parameter I where the functionality index was subdivided into opportune intervals and each was assigned a value of functional loss varying between low and high. 
Table 3: $\quad$ Functionality index and respective functional loss.

\begin{tabular}{|c|c|c|c|c|}
\hline $\begin{array}{c}\text { Functionality global index I of } \\
\text { system }\end{array}$ & $0-0,25$ & $0,25-0,5$ & $0,5-0,75$ & $0,75-1$ \\
\hline Loss of functionality & Low & Medium & High & $\begin{array}{c}\text { Very } \\
\text { high }\end{array}$ \\
\hline
\end{tabular}

\subsection{Phase 4: spatial analyses of the elements}

The fourth phase of the procedure concerns the implementation of the model in a GIS system in such a way as to represent the elements/objects that make up the territory and contribute to the definition of vulnerability so as to make the territory dynamic and easily updatable.

\section{Applications and results}

The decision to apply the proposed model of systemic vulnerability to the Basento River and the urban area of Potenza was based on the availability of studies and data which permitted a reliable reconstruction of scenarios and an assessment of the intensity of the flood event, as well as the existence of a complex territorial system presenting critical points linked to important risk elements such as regional roadways S.S 407 Basentana, railways, highway links Sicignano-Potenza), health (hospital San Carlo), professional (University, etc..) and industrial structures. The network of influence used to represent the territorial system is made up of 18883 elements including 1283 area elements, about 5000 linear elements and about 21000 punctual elements. The first group is made up of elements which correspond to the area covered by the census ISTAT of 2001; the second group refers to the road ways classified by the CNR with national validity and the third group is made up of buildings valued by Civilian Protection in 2004, which are of both private and public utility, industrial, public safety services (operative units) and medical services (health units). Important elements in the final assessment include the 14 operative units; San Carlo Hospital, nodes of the industrial and settled areas represented in the census area.

The system is characterized by specific damage scenarios selected in relation to the return time $(\mathrm{T}=30, \mathrm{~T}=200, \mathrm{~T}=500)$. These risk areas relate to the rivers Tiera, Gallitello, Tora, Rifreddo and to the river Basento.

This information was then superimposed on the map of the elements thereby identifying those directly involved for each return time period in a possible disaster event. The intensity of the flood event was calculated using the proposed approach for each scenario.

The evaluation of the global functionality index $I$ was obtained through the use of the equations proposed in the model and resulted as depending on the number of nodes at risk, their importance (greater or less vulnerability) and the intensity of the flood event. 


\section{Conclusions}

This work puts forward an approach for the evaluation of the consequences of natural disasters, specifically flood risk, developed through the utilization of a territorial model based on the theory of a network of influences and the introduction of a procedure for the evaluation of systemic vulnerability.

Its most innovative aspect lies in the scale change associated with the concept of vulnerability which is no longer considered simply as a characteristic of a particular element but is considered in relation to the territorial system as a whole.

The main aim of the proposed procedure is to function as a support to planning decisions in the analysis of the consequences of a flood event on an entire territorial complex leading to the definition of intervention priorities. Events which should be given first priority are those with the highest functional integrity $\mathrm{x}_{\mathrm{i}}$; while the proposed procedure also facilitates intervention on the elements more affected by systemic vulnerability.

Specifically, this model facilitates:

$>$ the definition of elements for priority intervention, which are those with the highest functional integrity values.

$>$ intervention regarding the elements more affected by systemic vulnerability;

$>$ the identification of functionality in a territorial system subject to flood risk because of the existence of functional links between the various elements,

$>$ the to evaluate the opportunity to make interventions (structural or managerial) on the system territory.

Systemic vulnerability analysis seems particularly appropriate for these rather complex territorial systems both in regard to the dimensions of the area studied as well as for the large number of elements directly involved in the immediate post emergency phases in the reception and delivery of services.

The reliability of the proposed approach was tested on a case study in the Potenza local area, an ideal area for the study of the consequences of flooding due to the availability of good hydrographic data regarding the Basento basin.

\section{References}

[1] Agogino, A.M. - (1999) - Management of uncertainty with influence diagrams. University of California in Berkeley, working paper 85-0703-6.

[2] Chirico, A. et al. (2002) - Progetto GERIA, la Gestione dei rischi naturali per la messa in sicurezza del territorio. Dossier tematico Valutazione di Vulnerabilità Sistemica nel territorio transfrontaliero.

[3] Ezell, B. C., Farr, J.V., \& Wiese, I. (2000) - Infrastructure risk analysis model. Journal of infrastructure system, 114-117.

[4] Fabietti, W. (1999) - Vulnerabilità e trasformazione dello spazio urbano, ALINEA Editrice, Firenze.

[5] Fera, G. (1991) - La città antisismica, Gangemi Editore, Roma. 
[6] Giosa, L., Manfreda, S., Pascale, S., Sdao, F., Sole, A. \& Albano, R. (2008) Assessment of systemic vulnerability in landslide and flood prone areas. Geophysical Research Abstracts, Vol. 10, EGU2008-A-03163, 2008 EGU General Assembly 2008.

[7] Haimes, Y. Y. \& Jiang, P. (2001) - Leontief-based model of risk in complex interconnected infrastructures. Journal of infrastructure system, 1-12.

[8] Lagomarsino, S., Giovinazzi, S. \& Lazzoni, L. (2002) - Il rischio sismico: valutazione della pericolosità, analisi della vulnerabilità fisica del costruito e scenari di danno. Dossier tematico - Progetto GERIA (Gestione dei Rischi Ambientali), Programma UE INTERREG II a, per la cooperazione transfrontaliera Italia - Francia, collana Territorio e Ambiente, Edizione del Delfino Moro, Alberga, 2002.

[9] Minciardi, R., Sacile, R., Taramasso, A.C., Trasforini, E. \& Traverso, S. (2004) - Valutazione della vulnerabilità di sistemi territoriali complessi soggetti a rischi di origine naturale: il caso della sollecitazione idrologica in Val Roja, Atti del Convegno VGR 2004 - Valutazione e Gestione del Rischio, Pisa, 19-21 October 2004.

[10] Pascale, S., Sdao, F. \& Sole, A. (2008) Assessment of systemic vulnerability in landslide prone areas: a proposed model. Sottoposto a Risk Analysis.

[11] Pascale, S., Sdao, F. \& Sole, A. (2007) - Assessment of systemic vulnerability in landslide prone areas: a proposed model. EGU 2007, Vienna - April 2007 - EGU 2007 Geophysical Research Abstracts, Vol. 9, 08659, 2007 SRef-ID: 1607-7962/gra/EGU2007-A-08659.

[12] Tamura, H., Yamamoto, K., Tomiyama, S. \& Hatono, I. (2000) - Modeling and analysis of decision making problem for mitigating natural disaster risks, European Journal of Operational Research 122, 461-468.

[13] Varis, O. (1997) - Bayesian decision analysis for environmental and resource management. Environmental Modelling \& Software, Vol. 12 (23), pp. 177-185. 